\title{
STUdy ANd ANAlysis OF MACHINe ANd TOOL PARAMETERS OF Stainless-Steel Turning USing Multi CoATEd ToOlS
}

\author{
Viktors Gutakovskis, Ajay Varma Buddaraju, Antons Steklejns, \\ Anita Avisane \& Gatis Muiznieks
}
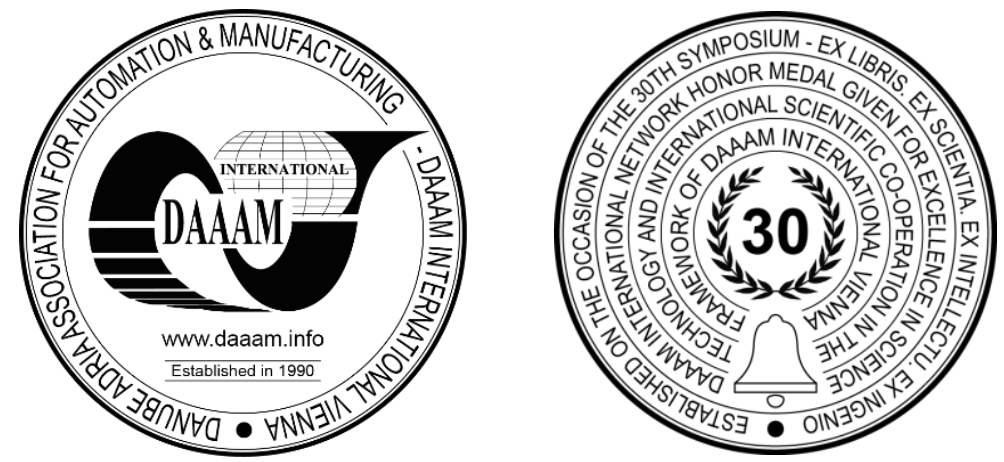

This Publication has to be referred as: Gutakovskis, V[iktors]; Buddaraju, A[jay] V[arma]; Steklejns, A[ntons]; Avisane, A[nita] \& Muiznieks, G[atis] (2021). Study and Analysis of Machine and Tool Parameters of Stainless-steel Turning Using Multi Coated Tools, Proceedings of the 32nd DAAAM International Symposium, pp.0555-0565, B. Katalinic (Ed.), Published by DAAAM International, ISBN 978-3-902734-33-4, ISSN 1726-9679, Vienna, Austria DOI: $10.2507 / 32$ nd.daaam.proceedings.080

\begin{abstract}
Metal cutting industries are confronted with the task of increasing production rate while lowering costs and improving final product quality. Manufacturing companies are under great pressure to discover and develop new technologies in order to fulfil increasing demands for productivity, closed tolerance, dimensional stability, and cost. As a result, coating an existing tool can help you enhance production rates, extend tool life, and save money. The purpose of this study is to optimize machining parameters including feed rate, depth of cut, and spindle speed when turning AISI316L using three coated tool inserts with different coatings. Using design expert software and response surface methodology (RSM), parameters in the direction of surface roughness are optimized. The condition of surface roughness was discovered to be ideal. For each solution, second-order polynomial models developed in this study were employed to attain the given ideal conditions. Derringer's desirability function technique was used to optimize several responses. The best surface roughness values found with CNMG 120404 coated with TiN (Titanium nitride), CNMG 120408 coated with TiAIN(Titanium aluminium nitride), and CNMG 120412 coated with AlCrN (Aluminum Chromium Nitride) are 1.311 $\mathrm{m}, 0.897 \mathrm{~m}$, and $0.965 \mathrm{~m}$, respectively. To validate the model, triplicate tests were performed under ideal conditions, and the mean values of the experimental data were compared to the expected values.
\end{abstract}

Keywords: Metal cutting; turning; lathe; stainless steel; AISI316L

\section{Introduction}

Because of the quick technical breakthroughs and digital advances, tool technology and production processes are particularly difficult to comprehend. It's crucial to use the correct material for production so that the product's design lasts. Cutting conditions, machining processes, tool geometry, chip formation, tool material, tool wear, and vibrations are all factors that affect the work material's quality. Cutting speed, feed rate, depth of cut, and tool noise radius are all frequent characteristics in the turning process. Austenitic stainless steel AISI 316L is used in a wide range of industries, including the chemical industry, nuclear power plants, and medical devices, due to its excellent mechanical properties and corrosion resistance. Machinability of stainless steel is an enthralling topic. 
Metal-cutting businesses face the challenge of increasing output while lowering costs and improving product quality. Manufacturing companies are under great pressure to discover and develop new technologies in order to fulfil increasing demands for productivity, closed tolerance, dimensional stability, and cost. As a result, coating an existing tool can help you enhance production rates, extend tool life, and save money. Modern businesses must deal with difficulties such as high-speed machining, hard turning, cutting difficult-to-cut materials, and dry machining. Thin layer coating was developed since this involves the use of coated equipment. Coated tools are used for a variety of purposes, including wear resistance, oxidation resistance, reduced friction, fatigue resistance, and thermal shock resistance. Aside from that, machining processes are intended to minimize the environmental impact of cutting fluid usage. Coated carbide cutting tools currently account for $80 \%$ of all machining operations in order to resolve the concerns described above.

A number of previous studies have documented the effects of cutting variables on traditional objective optimization (i.e. surface roughness, cutting force, material removal rate, and tool wear). And the vast bulk of the research was carried out with a specific objective in mind. Single-objective methods are typically used to determine the ideal value of a specific response and are limited to establishing the value of the optimum cutting parameters. In addition, lubricated stainless steel is regularly machined. Furthermore, better performance is necessary for hard finish turning when the necessary parameter circumstances are selected, due to the high cost of a CBN cutting edge." The purpose of this scientific work is to optimize the performance of a CBN tool in wet environments by adjusting machining parameters (such as feed rate, depth of cut, and spindle speed) with a stainless steel 316L coated tool insert. Using design expert software and response surface methodology (RSM), parameters are optimized. In addition, optimal conditions are attained.

\subsection{Aim of the work}

1. To study the turning of stainless steel $316 \mathrm{~L}$ on a CNC lathe machine with various parameter combinations using cooling.

2. To optimize the performance characteristics of various coating tool inserts using the Response Surface Methodology (RSM) approach to produce the lowest feasible surface roughness.

Tasks to achieve:

1. To receive experimental results on wet turning of stainless steel $316 \mathrm{~L}$ on a CNC lathe machine with different parameter combinations.

2. To use response surface methodology (RSM) to optimize the performance parameters for the lowest possible surface roughness

\section{Metal cutting using Turning Process}

As demonstrated in fig. 1, the turning process is clearly found in the machining method, which is a material removal approach for obtaining rotating components by cutting away undesired material by reducing its diameter. This turning procedure necessitates the task, fixture, and cutting tool. A pre-shaped material is fastened to the fixture in this piece, and it uses multi-point tools to complete numerous processes. The cutting device feeds into the rotating work piece or job, and the tool cuts material and generates chips in the desired shape. Self-assembly with the rotating device, allowing for faster rotation. The cutter is often a single-point cutting instrument that is also attached to the device.

This process is most commonly used to make rotatable, mainly axi-symmetric components with a range of features like holes, grooves, threads, tapers, multiple diameter steps, and curved surfaces. Components that are completely turned frequently contain parts that can be utilised in limited quantities, potentially for prototypes, such as bespoke produced shafts and fasteners. Turning is also a common approach to improve or add quality to components that have been manufactured in another means. Turning is useful for adding precise rotating functions to a factor when a standard shape has already been developed because of the higher tolerances and surface finishes it can deliver.

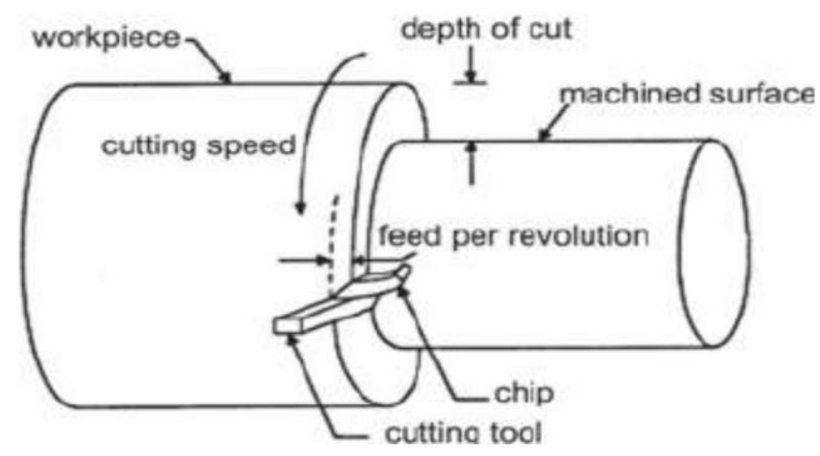

Fig. 1. Turning Process [1] 


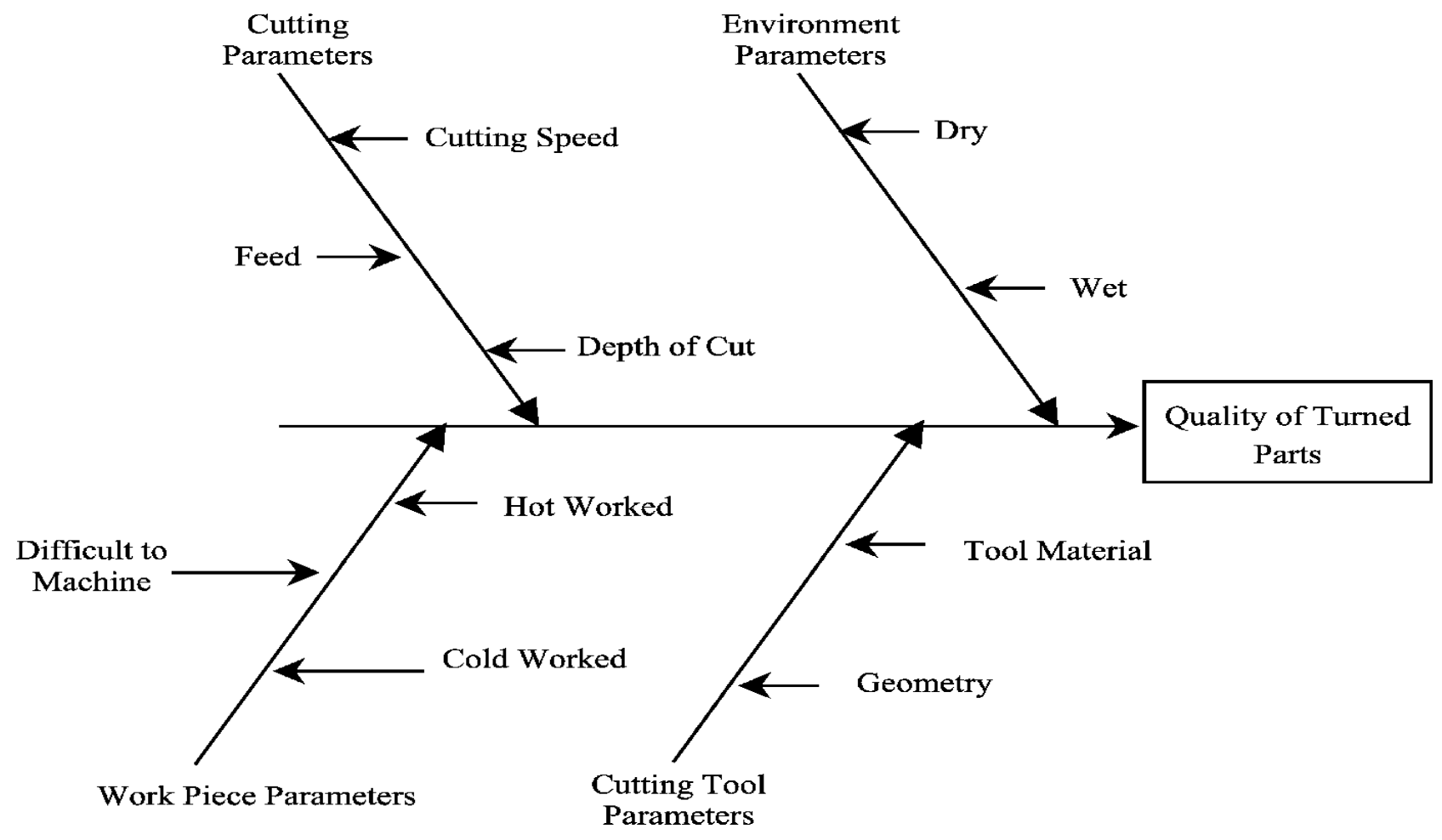

Fig. 2. Ishikawa cause- Effect diagram of a Turning process [2]

\subsection{Adjustable Cutting Factors in Turning}

Ishikawa cause and effect diagram has been created in an effort to recognise the process parameter that would affect the machining features of work pieces, as shown in fig. 2, Cutting tool parameters include tool shape and material, as well as cutting characteristics such as cutting velocity, feed, depth of cut, dry cutting, and wet cutting.

Spindle speed and cutting speed

The speed of the spindle and the work piece is frequently used to distinguish them. When expressed in revolutions per minute, it displays their rotating speed (rpm). However, for some turning operations, the surface speed, or the pace at which the work piece material goes past the cutting tool, is critical. Millimetres per minute are the measurement unit. Although the spinning speed remains the same, different work pieces with various diameters will always have a varying cutting speed.

Feed

It relates to how quickly the tool improves as it progresses along the cutting path. The feed of the tool affects both the tool's running speed and the surface roughness. As the feed rate increases, the running speed increases. When the feed is low, the outer surface polish is outstanding. There are two sorts of feeds: manual feeds that are manually turned and operated, and automated feeds that are automatically turned and operated. Manual mailing is recommended for beginners. Because serious accidents can occur, such as hitting the rotating chuck around the byte in all power-fed lathes' automatic feed.

Depth of Cut

"DOC" is a phrase that nearly goes without saying. "It can be defined as the thickness of the layer being removed (in a single pass) from the work piece, or the distance between the uncut and cut areas of the work, both in millimetres."

$\mathrm{D}$ and $\mathrm{d}$ represent the job's starting and ending diameters in millimetres. The diameter of the task, however, has shrunk by twice the depth of cut because this layer has been eliminated from both sides of the work.

\section{Cutting Tool Material selection}

For successful task completion, selecting the appropriate cutting tool material for a certain application area is critical. Cutting speeds can be increased to some amount to boost productivity, but they shorten tool life, raise the expense of regrinding / replacing the tool, and cause production issues.

There is no one-size-fits-all course that will satisfy all of your requirements. The tool's qualities are a compromise; for example, hardness increases, and hardness lowers in general. The following characteristics can be found in the contents of the ideal cutting tool. 
- Difficult compared to cutting work

- Maintains temperature stability

- Protects against wear and thermal stress.

- Impact resistance and chemical inertness

- Impact resistant and chemically inert

The machinist must have the following precise characteristics in order to successfully select a tool for machining:

- First, the shape and completion of the parts

- Hardness of working water

- Material tensile strength

- Material wear

- Generated chip type

- Preparing for employment

The machinist must always be involved in the performance and performance of the machine tool.

\section{Other research review}

Because of the growing demand for high-quality smooth surfaces, machining processes has been optimised. For decades, researchers have tried to optimise parameters that affect tool life, such as feed, depth of cut, and material hardness[3]. Tool life relates to how long a single point tool can function well before being declared failed, or how long a tool point can execute a metal cutting process before being pronounced failed. In every machining sector, the study of various types of tool inserts and the development of methods for monitoring tool life is a crucial feature that can save a lot of time and money. The tool life is greatly influenced by the material used to make it. Depending on the type of application, the current tool is coated with single or multi-layered materials such as titanium or carbide using CVD/PVD technology. Multi-layered coated carbide is cost-effective and has a superior surface polish for massproduction industries [4]. The amount of heat created during chip removal at the face and flank has a significant impact on tool performance during any metal cutting process. Furthermore, the tool undergoes physical and even chemical changes as a result of temperature and mechanical stress, causing the tool to lose its cutting characteristics and even fracture. Stainless steel is in high demand these days due to its high strength and low heat conductivity, despite its poor machinability [5].

Dabreo et al. [6] used a CNC lathe machine to conduct a turning experiment to estimate the tool life of a coated carbide insert in a wet environment. For this project, SS316L stainless steel was employed. The tool life was computed using the theoretical methodology (Taylor's tool life Equation), which took into account the number of jobs turned until it was pronounced fail. During the turning process, failure mechanisms of the tool were detected.

The compositions of Prasad et al. [7] coated inserts were identified, and their hardness was tested using X-ray diffraction analyses. "The grain structures of coatings were studied using scanning electron microscopy. Dry cutting experiments on AISI 304 stainless steel were conducted to evaluate the efficacy of various coatings in terms of wear and surface polish imparted to the workpiece. A 3D confocal laser microscope was used to examine the flank wear. A grey relation analysis was performed to optimize the machining parameters. The toughest coating was ncAlTiN/Si3N4coating, which measured $28 \mathrm{GPa}$, according to studies."

The coated carbide tool, as opposed to the traditional cemented carbide tool, is the most important cutting tool in the metal cutting business. According to Ghani et al. [8], utilizing a coated carbide tool reduces the coefficient of friction between the tool's rake face and the cut chip, improving cutting performance and lowering costs. Depending on the use, a variety of coating materials are available commercially. Some of these materials include "TiN (titanium nitride), TiCN (titanium carbinitride), AlTiN (aluminium titanium nitride), AlCrN (aluminium chromium nitride), Al203 (aluminium oxide), new ceramic coating, Cr-Based coating, and others. According to Uhlmannet al. [9], the innovative Cr-based coatings CrTiAIN and CrMoTiAIN had the smallest wear land width of all the coatings tested." PVD and CVD are two technologies for producing thin film layers with various coating layer topologies ranging from monolayer to multilayer.

TiN coating is the most commonly used coating in industry [10] because of its high hardness, corrosion and wear resistance, and gold-like appearance. Coated carbide cutting tools are carbide inserts coated with a range of materials, including titanium carbide (TiC), titanium nitride (TiN), and aluminium oxide (Al203) [11].

The flank wear of coated and uncoated carbide tools in tool steel bar turning was examined by Haron et al. [12]. (23HRC). A 350 diamond-shaped insert with simple groove was chosen to look at tool wear based on flank wear data." Coated carbide tools beat bare carbide tools in terms of performance, and flank wear was minimal. Wet machining for coated carbide tools is also better than dry machining because it reduces friction and heat, but chipping occurs at the end of tool life due to the substantial temperature gradient at the surface. Ashok Kumar Sahoo and bidyadhar Sahoo [13] investigated the machinability of uncoated and multilayer ( $\mathrm{TiN}$ and $\mathrm{ZrCN}$ ) coated carbide inserts in finish hard turning of AISI 4340 steel. 
According to the conclusions of this study, coated carbide inserts had a longer tool life, lower machining forces, and lower machining costs than uncoated carbide inserts. According to the quantitative data, the tool life of $\mathrm{TiN}$ and $\mathrm{ZrCN}$ coated carbide inserts was 19 and 8 minutes, respectively. Coated carbide inserts reduced machining costs by 93.4 percent, whereas $\mathrm{ZrCN}$ coated carbide inserts cut expenses by $40 \%$.

Federico et al.[14] "reported that the coated carbide tool is also used for cutting hardened steel in his study of hardened steel using TiCN/A1203/TiN coated carbide and PCBN tools. Machine hardened steel with a TiCN/A1203/TiN coated carbide cutting tool was both productive and cost-effective, according to the findings. Kaladhar et al. [15] conducted an experiment to evaluate the efficiency of coated materials in machining austenite stainless steel. The results revealed that a PVD-coated TiAIN-TiN insert produces the best surface finish. Yigit et al.[16] investigated the performance of multilayer TiCN/TiC/A1203/TiN and TiCN/TiC/Al203/TiN carbide tools with an external TiN layer and found that TiN's high hardness improves wear resistance and lowers surface roughness in hard turning. Noordin et al.[17] studied AISI steel turning with two types of coated carbide, one with an A1203 outer layer and the other with a TiN layer. They discovered that a tool with a TiCN/TiN CVD/TiN and TiN PVD coating sequence generated the best results, with lower cutting forces, great surface quality, and a chip with a tiny secondary shear zone."

Aurich et al. [18] investigated the effect of four different coating methods on hot AISI4140 steel turning: TiN, TiN/TiAlN/TiN, TiN/TiCN/Al2O3, TiN/TiCN/Al2O3/TiN. The TiN/TiCN/Al2O3/TiN multilayer coating system had the smallest crater depth, while the TiN-TiCN-Al2O3-TiN coating system had the longest tool life travel. When cutting AISI1015 steel, Hasan and Muammer [19] looked at how surface roughness was affected by uncoated and coated carbide tools. They tested three-layer coatings with TiN outermost layer, AlTiN, TiAlN, and three-layer coatings with TiN outermost layer, finding that three layer coatings with TiN outermost layer improve surface roughness."

Kulkarni et al. [20] optimised cutting settings for dry turning of austenitic stainless steel AISI 304 with an ALTICRN coated tool. A fine-grained K-grade (ISO K-20) cemented carbide cutting insert received the coating via a physical vapour deposition (PVD) procedure. As turning parameters, cutting speeds of 200 and $260 \mathrm{~m} / \mathrm{min}$, feed rates of 0.20 and $0.26 \mathrm{~mm} / \mathrm{rev}$, and coating thicknesses of 3.6 and $4.6 \mathrm{~m}$ at two levels were examined.

To improve the surface roughness and turning of EN8 medium carbon steel, Inamdar et al. [21] employed the Taguchi technique. Feed rate and cutting depth at working speed are utilised to improve surface roughness. The Taguchi methodology is used to calculate the effect of the principal surface roughness parameters using levels and coefficients. Experiments can be designed using L9 orthogonal arrays. 95\% of the important factors were also investigated (ANOVA). Cutting speed, rather than feed rate or cutting depth, appears to have a greater impact on surface sharpness in the turning process, according to the data.

Kumar \& Shanmuga [22] chose the cutting speed, feed rate, and cutting depth based on the cutting parameters. Before beginning the experimental machining method, the ideal range of cutting parameters for Martentic Stainless Steel 416 machining is chosen. Assemble as many parameter combinations as possible. Change the cutting parameters and see what happens (surface roughness, cutting force). After you've optimised your machining skills, use Minitab software to implement the widely used Taguchi method. The Taguchi method is simple and effective, yielding the optimal set of machining parameters. Finally, a check test of precise machining parameters was done to ensure the reliability of the previously collected experimental results. The verified results were regarded exceptional and appropriate. Padma et al. [23] used a Taguchi and Gray Relative Analysis combination to optimise EN 9 and carbon steel turning process parameters, utilising gears as hooks) to deliver the least cutting power and the least rough surfaces for lathes. The trials with the L9 orthogonal array, as well as Taguchi's experimental design, are now complete. Analysis of variance was used to assess the principal impact of the experimental data' processing parameters (ANOVA). In addition, both the process parameter and the answer were flipped. The final result, which depicts the true cutting depth, is an important factor in the effects of cutting force and surface roughness that transfer and cutting oil consider.

Jagade et al. (2917) aimed for the highest quality in terms of partial accuracy, surface finish, and speed. As a result, selecting the appropriate machining parameters is critical for lowering production costs while also ensuring product quality. This study provides a review of the current literature for in-depth investigations on optimising process parameters in CNC turning operations. It aids understanding of the impacts and effects of CNC input process parameters on response variables in this research. To optimise the process of determining the most significant parameters, the Taguchi and ANOVA techniques were applied.

The surface of the EN47 material was studied by Sharma et al. (2017). Various cutting settings were used in the $\mathrm{CNC}$ lathe testing. Hard turning produces great surface roughness, according to research. The rotational performance characteristics of the EN 47 combination material applied by the composite site were investigated using the L9 orthogonal sequence, which shows sound relationships and deviation analysis (TNMG 160408-FMTN8135). The proposed surface sharpening styles for the materials currently under consideration were created, evaluated, and evaluated using new data.

Maheswara Rao and K. Venkatasubbaiah (2016) Cutting parameters (spindle, feed, and cutting depth) of the AA7075 CNC lathe on low surface roughness with tungsten carbide insert were investigated. The Taguchi orthogonal array was used to construct it in the research. Analysis of variance was used to examine the importance of parameters cut by surface roughness (ANOVA). The ideal range of surface roughness levels was then calculated after that. Finally, a collaboration between variable cutting and MINITAB-16 application inference was built, and regression analysis was conducted. As you can see, the values produced by comparing anticipated and experimental values are quite near, indicating that the model is accurate and adequate. 
M Ganesh et.al (2015) While confining the EN-8 metal, he employed a genetic algorithm to optimise the processing elements and set the surface roughness. For spindle speed, feed rate, and cutting depth, this research focuses on CNC rotation with cemented carbide tools. The minimal surface area $(\mathrm{Ra})$ produced by GA is 2.51 . The ideal simulation for attaining the highest possible linear model adaptation is the genetic algorithm.

Using the Taguchi methodology, Krupalpawar et al. (2015) evaluated the influence of variations in tool nose radius on surface sharpness and MRR, ANOVA analysis, and inverse SSS. Nose radius on CNC lathes: 0.4, 0.8, and 1.2mm The annotation coated carbide tip tool is configured to allow high-speed river turning of SSS (M2) and research variables employing four parameters in three steps.

Rajpoot Bheem Singh et al. (2015) used the surface response methodology to assess the effects of cutting settings on average surface clarity and material removal rates when turning Al 6061 alloys. RSM was used to determine the effect of each element of surface sharpness separately. The image's sharpness was determined using three separate points. We utilised Design Expert 8.0.4.1 software to analyse the results of 20 tests to determine surface roughness and material loss rates. Surface roughness has been assessed using regression models that take into consideration actual parameters. The significance of regression models was investigated using an ANOVA with a 95\% confidence level. Cutting speed, which is one of three cutting parameters, was found to effect surface roughness and MRR.

\section{Methodology and experimentation}

The purpose of this work has already been discussed in previous chapter. Therefore, this study was conducted through the following steps.

1. First, check and prepare the machine to perform the machining work.

2. Cut the stainless-steel rod using the electric saw and perform the first turning of the part to get the desired dimensions of the work piece $(50 \mathrm{~mm}$ in diameter and $250 \mathrm{~mm}$ in length).

3. After cutting the work piece, turn the workpiece in a wet condition according to the Box-Behnken design.

4. The cutting length was maintained constant at $5 \mathrm{~mm}$.

5. After processing, the next step is to measure the surface roughness. This work is done with the help of the portable stylist Talysurf Profiler.

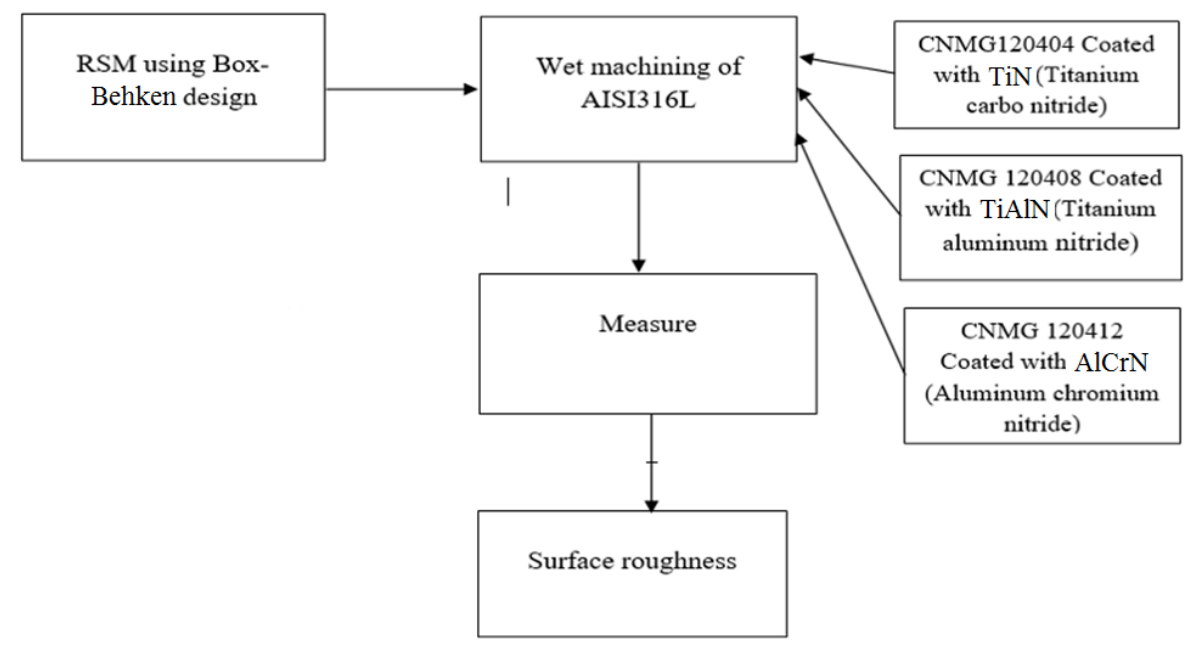

Fig. 3. Experimetal work chart.

\section{Selection of Process Parameters and their Levels}

After doing a literature research, the parameters and their levels are determined. According to the literature review, the experimental process parameter ranges have been finalised. The outcomes of the pilot studies were also taken into account. The parameters' stages were determined based on the outcomes of pilot tests. The process variables in this experimental investigation were the parameters chosen. Table 1 shows the parameters for machining with units (and notations).

\begin{tabular}{|c|l|c|c|c|}
\hline \multicolumn{2}{|c|}{ Parameters/Factors } & \multicolumn{3}{c|}{ Level } \\
\cline { 3 - 5 } & Spindle speed (rpm) & 500 & 0 & 1 \\
\hline A & F & 0.15 & 000 & 800 \\
\hline C & Deepth of cut $(\mathrm{mm})$ & 0.4 & 0.17 & 0.2 \\
\hline
\end{tabular}

Table 1. Process variables and their limits 


\section{Material selection}

Austenitic stainless steel AISI 316L was chosen for this study due to its excellent mechanical properties and corrosion resistance. Chemical plants, nuclear power plants, and medical gadgets all use it. It's fascinating to look into stainless steel machinability. [2].

\begin{tabular}{|c|c|c|c|}
\hline Tensile strength, MPa & Yield strength, MPa & Elastic modulus, GPa & Poisson's ratio \\
\hline 515 & 205 & $190-210$ & $0.265-0.275$ \\
\hline
\end{tabular}

Table 2. Mechanical property of AISI 316L

\begin{tabular}{|c|c|c|c|c|}
\hline Element & Iron, Fe & Chromium, Cr & Nickel, Ni & Manganese, Mn \\
\hline$\%$ & 71.935 & 16.439 & 10.032 & 1.594 \\
\hline
\end{tabular}

Table 3. Chemical property of AISI316L

\section{Cutting tool insert}

Coated carbide tools have been shown to outperform uncoated carbide tools when it comes to turning steel. As a result, a commercially available CVD coated carbide insert was used in this investigation. CNMG 120404, 120408, and 120412 nose radius of $0.4,0.8$, and $0.12 \mathrm{~mm}$ were used with WIDIA multi-layer coated cutting inserts. Cutting tool geometry is shown in Table 3.5.1. The manufacturer's instructions was used to choose the cutting tool. Three cutting tool inserts with different coatings were employed in the wet turning of AISI316L in this investigation, as they are often utilised in AISI316L machining.

1. CNMG 120404 coated with TiN (Titanium carbo nitride)

2. CNMG 120408 coated with TiAIN (Titanium aluminum nitride)

3. CNMG 120412AlCrN (aluminum chromium nitride)

\section{Design of Experiment}

A total of fourteen trials were done. Each trial experiment was repeated three times. The turning was done in a completely dry environment. To determine the effect of factors on responses, the RSM approach was utilised. The RSM experimental model is depicted in Table 3.2. RSM [13,14] outlines a method for determining the link between causes and responses. The following is the functional relationship between the response $\mathrm{Y}$, variable $\mathrm{Xj}$, and the levels of the $\mathrm{n}$ input variables (1):

$\mathrm{y}=\mathrm{f}\left(\mathrm{X}_{1}, \mathrm{X}_{2}, \mathrm{X}_{3}, \ldots \ldots \ldots . . . \mathrm{Xn}\right)$

If the answer can be described by a linear function of independent variables, then the approximation function is a firstorder model. A first-order model with two independent variables can be stated as follows (2):

$\mathrm{y}=\beta_{0}+\beta_{1} x_{1}+\beta_{2} x_{2}+\varepsilon$

If the response surface is curved, you should use a higher degree polynomial. An approximation function with two variables is specified as a second-order model (3):

$\mathrm{y}=\beta_{0}+\beta_{1} x_{1}+\beta_{2} x_{2}+\beta_{11} x_{11}^{2}+\beta_{22} x_{22}^{2}+\beta_{12} x_{1} x_{2}+\varepsilon$

Fourteen experiments have been performed as per above experimental plan by using one cutting tools. A total of 42 $(14 * 3)$ experiments have been performed with three cutting tool inserts with different coatings under wet conditions.

\section{Data Collection}

Surface roughness measurements.

Turning tests with a cutting length of $220 \mathrm{~mm}$ were carried out on a CNC machine. A cylinder made of AISI316L with a diameter of $50 \mathrm{~mm}$ and a length of $250 \mathrm{~mm}$ was used as the work piece. Three cutting tool inserts with different coatings were employed in the wet turning of AISI316L. The machining tests were carried out on a DoE planed with a Box-Behnken design that included three variables and three levels, for a total of 14 experiments. The test was conducted with Mitutoyo's Surftest SJ 201 surface roughness tester. The probe was changed in order to find the Ra value. Three millimetres were added to the probe's length (see fig.4.) 


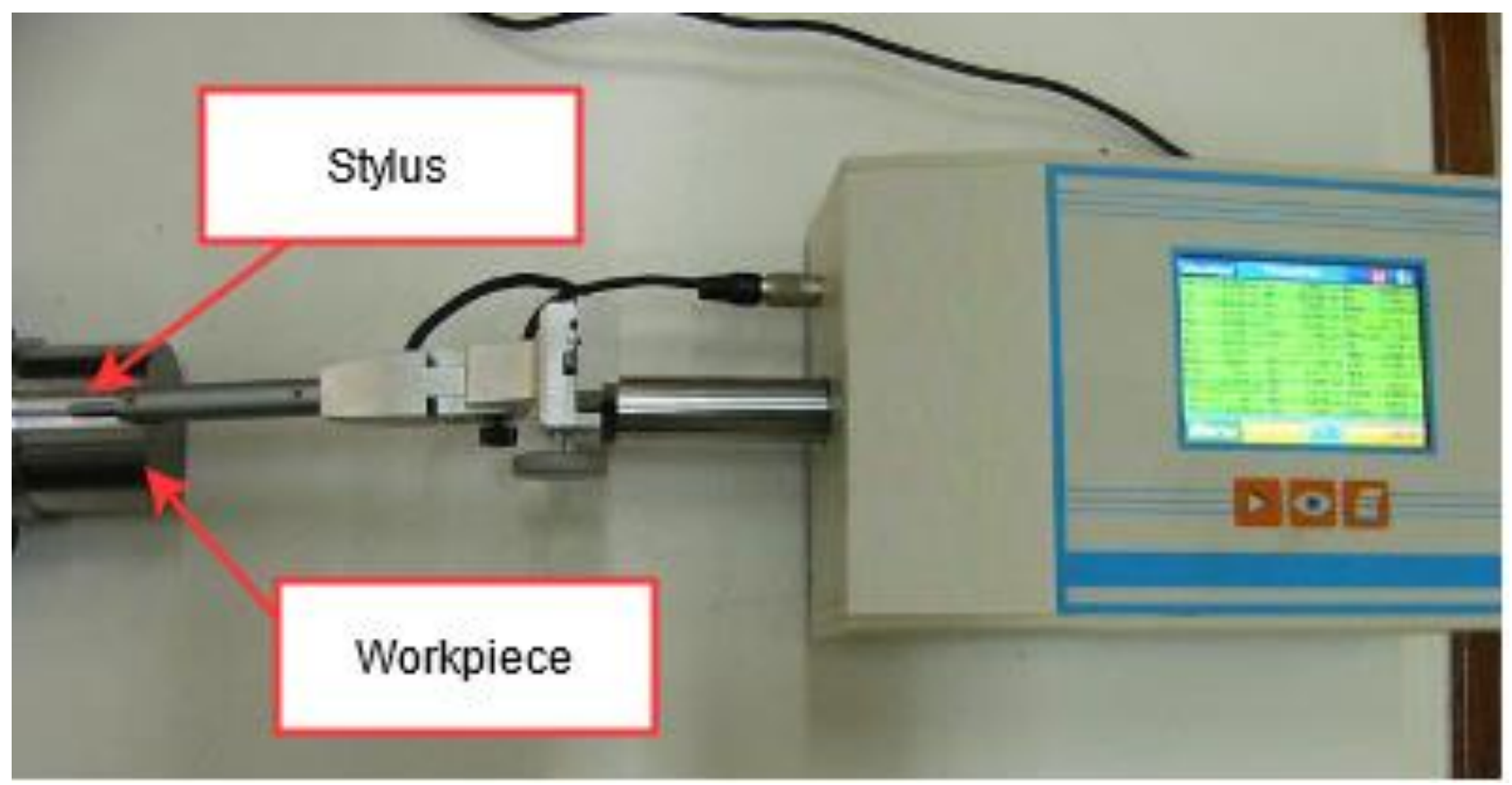

\section{Results and discussion}

Fig. 4. Surface roughness tester.

\section{Adequacy of the Model}

The statistical analysis was performed using Design Expert Statistical Software package (8.1 trial version) (State Ease Inc., Minneapolis, USA). The experimental data were analyzed using multiple regressions and significance of regression coefficients were evaluated by F-test and the significance of the F-values were verified at probability levels $(\mathrm{p}<0.05)$. Modeling was started with a quadratic model including linear, squared, and interaction terms. The model adequacies were checked in terms of $\mathrm{R}^{2}$, adjusted $\mathrm{R}^{2}$, and prediction errors sum of squares. The significant terms in the model were found by Pareto analysis of variance (ANOVA). For each response, ANOVA table was generated. The regression coefficients were used to make statistical calculations to generate response surface plots from the regression models. The responses were optimized by numerical optimization technique using Derringer's desirability function method. This function searches for a combination of factor levels that jointly optimize a set of responses by satisfying the requirements for each response in the design.

The optimization was accomplished by three steps, i.e. converting each response $\mathrm{Yi}(\mathrm{i}=1,2, \ldots, \mathrm{m})$ into a dimensionless desirability scale that defines a partial desirability function (di), combining the individual desirabilities to obtain global desirability function (D), and finally identifying the optimal factor settings. The desirability function's scale ranges between0 (completely undesirable response) and 1 (fully desired response). The individual desirabilities (d) for each response were obtained by specifying the goals, i.e. minimize, maximize, or target the response, and boundaries required for each one. A weight factor was assigned which explains the shape of the desirability function for each response. The suitability of the developed model equations for predicting the optimum response values was verified using the optimal conditions. Triplicate experiments were carried out in the optimal condition and the mean experimental values were compared with the predicted values in order to determine the validity of the models.

Surface roughness vs. cutting parameters such as spindle speed $(\mathrm{rpm})$, feed rate $(\mathrm{mm} / \mathrm{min})$, and cut depth are plotted in this section (mm). As illustrated in Fig.5,6,7 the visualization of residual vs. run number exhibits a similar pattern with little change across treatments. There is no proof that the procedure has been slowed down. It's useful to figure out how reliable a result is and how skilled a researcher is at running them. The graphic displays random scatter residuals that are contained within the stated domains and do not exceed them, indicating that the model is valid. The residuals are placed on the up and down sides of the straight center line at random. When it comes to answers, the residuals are usually between 2 and -2 . As a result, the errors are spread in a natural fashion (see fig.5,6,7.). 
Design-Expert ${ }^{\circledR S o f t w a r e ~}$

Surface roughness

Color points by value of Surface roughness:

$1.245 \square 1.578$

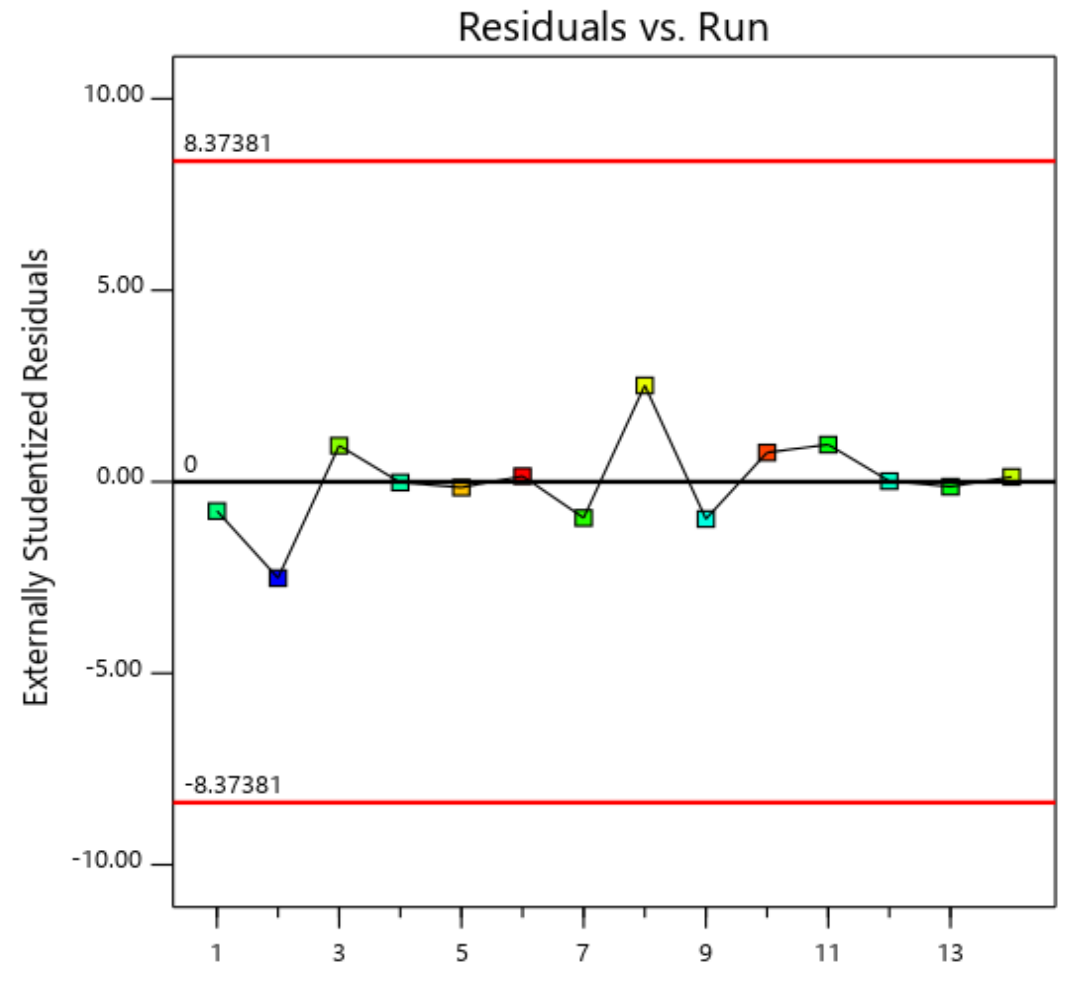

Run Number

Fig. 5. Residuals vs run plot for a surface roughness achieved with CNMG 120404 coated with TiN

Design-Expert ${ }^{\circledR}$ Software

Surface roughness

Color points by value of

Surface roughness:

0.854

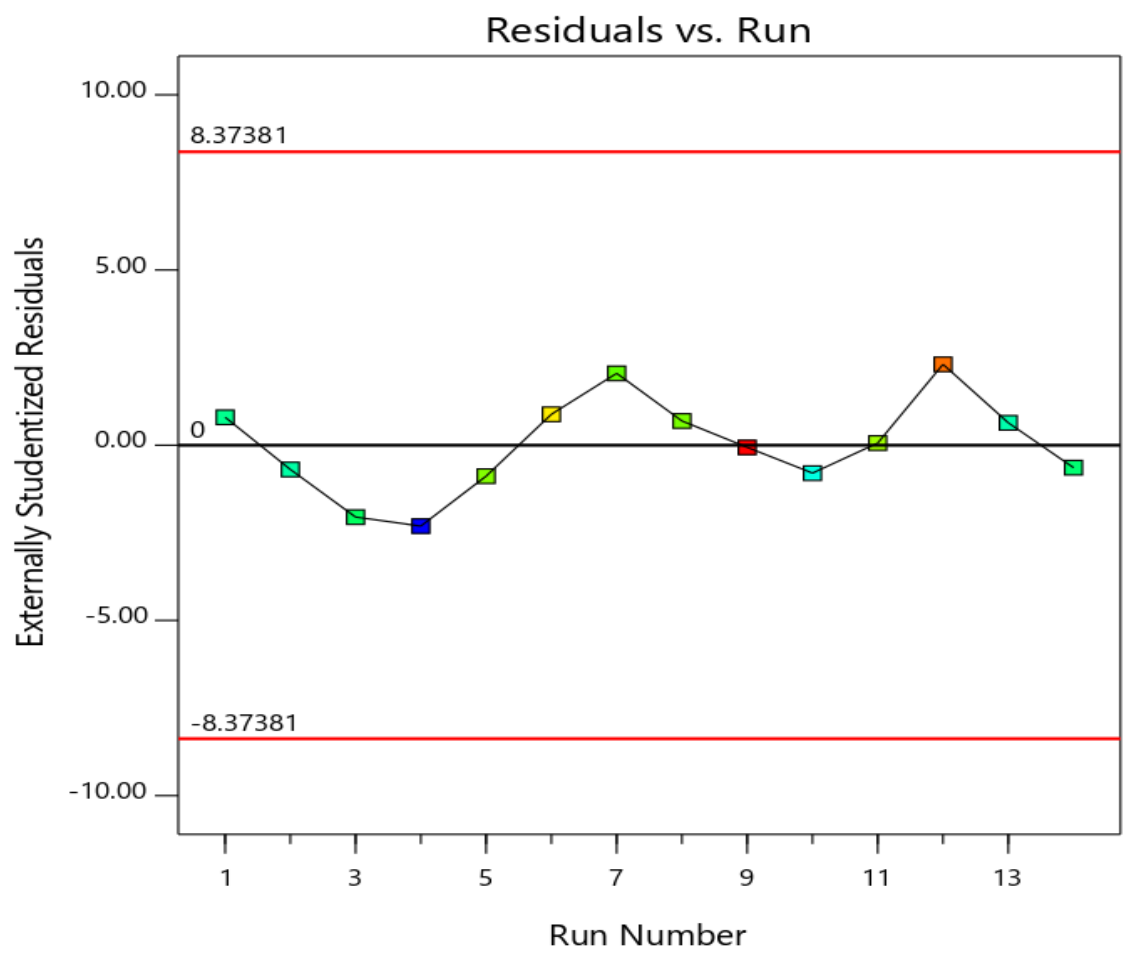

Fig. 6. Residuals vs run plot for a surface roughness achieved with CNMG 120408 coated with TiAIN (Titanium aluminum nitride) 

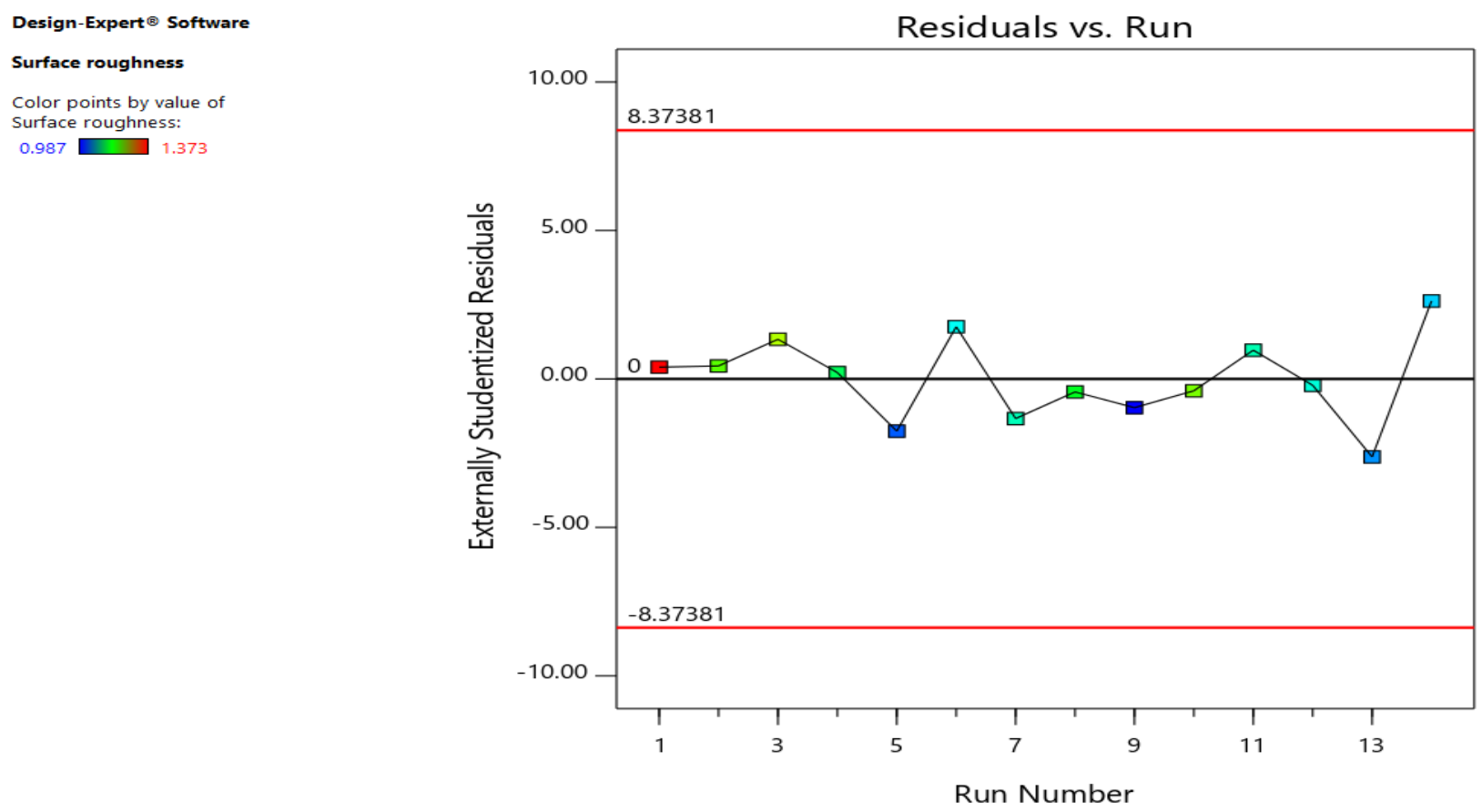

Fig. 7. Residuals vs run plot for a surface roughness achieved with CNMG 120412 AlCrN (aluminum chromium nitride)

\section{Selection of Optimum Conditions}

Surface roughness was found to have an optimal condition. Second-order polynomial models developed in this study were employed for each answer in order to attain the given optimum conditions. Derringer's desirability function technique was used to optimize a large number of responses. With CNMG 120404 coated with TiN, the best surface roughness was achieved, CNMG 120408 coated with TiAIN and CNMG 120412 coated with AlCrN is obtained as $1.311 \mu \mathrm{m}, 0.897 \mu \mathrm{m}$ and $0.965 \mu \mathrm{m}$.

\section{Conclusions}

Using three different cutting tool inserts, this study shows how to optimise process parameters in wet turning of AISI 316L. To optimise turning process parameters, the RSM method is employed. An ideal state of surface roughness was discovered. Second-order polynomial models developed in this work were employed for each answer in order to achieve the given optimum conditions. Using Derringer's desirability function method, many responses were optimized. As a result, the following conclusion can be derived from the current research:

1. The optimum surface roughness achieved with CNMG 120404 coated with TiN, CNMG 120408 coated with TiAINand CNMG 120412 coated with AlCrN is obtained as $1.311 \mu \mathrm{m}, 0.897 \mu \mathrm{m}$ and $0.965 \mu \mathrm{m}$.

2. The plot shows random scatter residuals that are contained inside and do not exceed the stated domains, showing that the model is viable. The residuals are dispersed along the up and down sides of the straight centre line at random. Residues are normally between 2 and 2 for replies. As a result, the mistakes are evenly distributed.

3. To confirm and check the normality assumption, a normal probability plot of the residual was constructed. According to the findings, the largest residuals are not as large as expected. Because there are no outliers and the linear deviations are small, the experiment produces a desirable outcome that fits the normality assumption.

4. The ANOVA approach is used to determine the model's relevance in predicting surface roughness. The response surface roughness produced by CNMG 120404 coated with TiN, CNMG 120408 coated with TiAIN, and CNMG 120412 coated with $\mathrm{AlCrN}$ had R2 values of $0.9657,0.9734$, and 0.9788 , respectively, indicating that the model suited the experimental data reasonably well. The R2 values were changed as $0.9515,0.9645$, and 0.9634 respectively. The expected R2 values were $0.9497,0.9551$, and 0.9568 , respectively. The correlations between surface roughness and process factors were found to adequately account for data variability. The adjusted R2 and anticipated R2 values showed a high degree of connection between observed and expected values. The quadratic regression model's ANOVA shows that it was very significant. This was evident from the Fisher's F-Test (F value = 19.6871 cutting with CNMG 120404 coated with TiN, F value = 114.01 cutting with CNMG 120408 coated with TiAIN and $\mathrm{F}$ value = 203.03 cutting with $\mathrm{CNMG} 120412$ coated with $\mathrm{AlCrN}$ ) and a very low probability value ( $\mathrm{p}=$ 0.0001). 
5. "To validate the model, triplicate tests were performed under ideal conditions, and the mean values of the experimental data were compared to the expected values. According to the findings, the percentage difference between expected and experimental surface values ranged from 3.71 percent to 11.51 percent."

6. The research plans will be targeted on using more perspective tools, for example with Duratomic- coating technology (Seco) and other Stainless Steel grades, like AISI 304 and AISI 420.

\section{References}

[1] Buldum, Baris \& Eşme, Uğur \& Kulekci, Mustafa \& Tarsun-Mersin, \& ŞIK, Aydın \& Ankara, \& Kazançoğlu, Yiğit. (2012). Use of Grey-Taguchi Method for the Optimization of Oblique Turning Process of AZ91D Magnesium Alloy. Materials Testing. 54. 779-785.

[2] Gill, Dr. Surinder \& Gupta, Meenu \& Satsangi, P.. (2015). Multiple-response optimization of cutting forces in turning of UD-GFRP composite using Distance-Based Pareto Genetic Algorithm approach. Engineering Science and Technology, an International Journal. 3. 10.1016/j.jestch.2015.04.010.

[3] Ghubade, A., Gupta, A., Abrol, A., \& Singh, S. (2015). Study of Uncoated and Coated Carbide Insert on Tool Life, Surface Roughness and Material Removal Rate in Machining of EN27 steel. Journal for Manufacturing Science and Production, 15(2).

[4] Klocke F, Krieg T. Coated tools for metal cutting - features and applications. Ann Rhe ClRP 48:7999.3.

[5] Grzesik W. (1998), The role of coatings in controlling the cutting process when turning with coated indexable inserts. J Mater Process Technol; 179:133-43.

[6] Al-Ahmari A M A )2008(. Prediction and optimization models for turning operations, International Journal of Production Research, 464061-81.

[7] Dasgupta S and Mukherjee S )2016(. Effects of machining parameters on tool life and its optimization in turning mild steel with brazed carbide cutting tool, IOP Conf. Ser.: Mater. Sci. Eng. 149012005.

[8] Tamrakar R and Vishwakarma D U )2017(. A Review on Optimization of Cutting Parameters for Tool life and Surface Roughness in Turning Process 34.

[9] Prince Dabreo, Samhita Pashte, Larisa Dmonte, Lavin Dabre (2021). Estimation of Tool Life by Industrial Method and Taylors Method Using Coated Carbide Insert in Turning of Work- Material SS3161, IOP Conf. Series: Materials Science and Engineering, 1070.

[10] Kaushik Vijaya Prasad, Ratna Pal, and Vishnu Kuncham Rajendra Prasad (2016). Optimization of Cutting Parameters during Dry Turning of Austenitic Stainless Steel Using nc-AlTiN/Si3N4, TiAlN, and TiN Coated Inserts. Journal of Materials, Volume 2016, Article ID 3495698, 5 pages.

[11] Ghani JA, Choudhury IA, Masjuki HH. Wear mechanism of TiN coated carbide and uncoated carbide tools at high cutting speed application. J Mater Process Technol 2004; 153-154:1067-73.

[12] Uhlmann E, Wiemann E, Yang S, Krumeich J, Layyous A. New coating developments for high performance cutting tools.

[13] Stoiber M, Badisch E, Lugmair C, Mitterer C. Low-friction TiN coatings deposited by PACVD. J Surf Coat Technol 2003; 163-164:451.7.

[14] Sahin Y, Motorcu AR. Surface roughness model for machining mild steel with coated carbide tool. Mater Des $2005 ; 26: 321-6$.

[15] Che Heron CH, Ginting A, Goh JJ. Wear of coated and uncoatedcarbides in turning tool steels. J Mater Process Technol 2001; 116:49-54.

[16] Ashok Kumar Sahoo Bidyadhar Sahoo. (2012). Experimental investigations on machinability aspects in finish hard turning of AISI4340 steel using uncoated and multilayer coated carbide inserts. Measurement; 45: $2153-65$.

[17] Federico MA, Coelho Reginaldo T, Brandao Lincoln C. Turning hardened steel using coated carbide at high cutting speed. JBraz Soc Med Sci Eng 2008;30:104-9.

[18] Kaladhar M, Venkata Subbaiah K, Srinivasa Rao Ch. Performance evaluation of coating materials and process para-meters optimization for surface quality during turning ofAISI304 austenitic stainless steel. Inter J Eng Sci Technol2011;3:89-102.

[19] Yigit R, Erdal C, Fehim F, Sakip K. Tool life performance of multilayer hard coatings produced by HTCVD for machining of nodular cast iron. Int J Refract Met Hard Mater 2008; 26: 514-24.

[20] Noordin MY, Venkatesh VC, Chan CL, Abdullah A. (2012). Performance of cemented carbide tools in turning AISI 1010 steel. J Mater Process Technol; 116: 16-21.

[21] Auricha JC, Eyrischa T, Zimmermanna M. (2012). Effect of the coating system on the tool performance when turning heat treated AISI4140. Procedia CIRP; 1:214-9.

[22] Hasan Gokkaya, Muammer Nalbant. (2006). The effects of cutting tool coating on the surface roughness of AISI 1015 steel depending on cutting parameters. Turkish J Eng Environ Sci; 30:307-16.

[23] Kulkarni, Atul \& Joshi, Girish \& Sargade, Vikas. (2013). Design optimization of cutting parameters for turning of AISI 304 austenitic stainless steel using Taguchi method. Indian Journal of Engineering and Materials Sciences. 20. 252-258. 